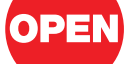

SUBJECT AREAS:

ALZHEIMER'S DISEASE

MOTOR NEURON DISEASE

PARKINSON'S DISEASE

GLIAL BIOLOGY

Received

4 October 2012

Accepted

14 February 2013

Published

19 March 2013

Correspondence and requests for materials should be addressed to

B.A.N. (b.neilan@ unsw.edu.au)

\section{Gliotoxicity of the cyanotoxin, $\beta$-methyl-amino-t-alanine (BMAA)}

\author{
Alexander S. Chiv' , Michelle M. Gehringer ${ }^{1}$, Nady Braidy ${ }^{2}$, Gilles J. Guillemin ${ }^{3,4}$, Jeffrey H. Welch' \\ \& Brett A. Neilan'
}

${ }^{1}$ School of Biotechnology and Biomolecular Sciences, University of New South Wales, Sydney, NSW, 2052, Australia, ${ }^{2}$ School of Psychiatry, University of New South Wales, Sydney, NSW, 2052, Australia, ${ }^{3}$ St Vincent's Centre for Applied Medical Research, St Vincent's Hospital, Victoria St, Darlinghurst, Sydney, NSW, 2010, Australia, ${ }^{4}$ School of Medical Sciences, University of New South Wales, Sydney, NSW, 2052, Australia.

The amino acid variant $\beta$-methyl-amino- ${ }_{-}$-alanine (BMAA) has long been associated with the increased incidence and progression of the amyotrophic lateral sclerosis/Parkinsonism dementia complex (ALS/ PDC). Previous studies have indicated that BMAA damages neurons via excitotoxic mechanisms. We have challenged rat olfactory ensheathing cells (OECs) with exogenous BMAA and found it to be cytotoxic. BMAA also induces a significant increase in $\mathrm{Ca}^{2+}$ influx, enhanced production of reactive oxygen species (ROS), and disrupts mitochondrial activity in OECs. This is the first study investigating BMAA toxicity using pure glial cells. These findings align BMAA with the three proposed mechanisms of degeneration in ALS, those being non-cell autonomous death, excitotoxicity and mitochondrial dysfunction.

he modified amino acid, $\beta$-methyl-amino- ${ }_{-}$-alanine (BMAA), has long been associated with the elevated incidence of the amyotrophic lateral sclerosis/Parkinsonism dementia complex (ALS/PDC) within the local Chamorro people of $\mathrm{Guam}^{1-3}$. It has been repeatedly suggested that exposure to BMAA is also associated with the development of other neurodegenerative disorders, such as Alzheimer's disease (AD) ${ }^{4-7}$. Numerous in vitro investigations conducted on mice, rat, leech, and recently human cells, have revealed the detrimental effects of BMAA to neurons ${ }^{8-17}$. Excitotoxicity, the process of cell death occurring due to activation of excitatory amino acid (EAA) receptors (notably glutamate receptors), is the most commonly implicated mechanism of action for this naturally occurring compound ${ }^{8-17}$.

In vivo, neuronal cells are dependent on support from glial cells and neurotrophic factors to function efficiently. The olfactory ensheathing cell (OEC) is a specialized glial cell that associates with the olfactory nerve, surrounding the sensory axons as they leave the olfactory epithelium and accompanying them from the nose to the brain ${ }^{18}$. Physiologically OECs exist both inside and outside the central nervous system and have the ability to generate neurons throughout adult life ${ }^{19}$. In medical research, they have been used extensively as transplant cells in both accidental and neurodegenerative pathologies and have shown the ability to functionally adapt to different microenvironments in which they have been transplanted ${ }^{20,21}$. The expression of a variety of functional glutamate receptor subtypes have previously been characterised in glial cells $\mathrm{s}^{22}$, however, the excitotoxic potential of BMAA on pure glial cells has not yet been determined. Previous observations have concluded that BMAA causes no damage to glial cells, although these observations were made on mixed cultures containing a variety of cell types, and did not rely on data from thorough toxicological assays ${ }^{11,13,16}$.

The main objective of this study was to investigate the in vitro effects of BMAA on glial cells. We monitored the effects of BMAA on mitochondrial activity, cell viability, $\mathrm{Ca}^{2+}$ influx and generation of reactive oxygen species (ROS). The results provide greater insight into BMAA's potential role in neurodegeneration, with particular emphasis on the non-cell autonomous death mechanism of neuronal degradation which is central to the proposed aetiology of $\mathrm{ALS}^{23}$.

\section{Results}

Cytotoxicity effects of BMAA on OECs. BMAA induced a significant $(\mathrm{p}<0.001)$ increase in lactate dehydrogenase (LDH) release from OECs at $100 \mu \mathrm{M}, 500 \mu \mathrm{M}$ and $3 \mathrm{mM}$ exposure concentrations (Fig. 1A). The greatest LDH release occurred at $500 \mu \mathrm{MBMAA}(15.57 \pm 0.22 \%)$ compared to the control $(12.40 \pm 0.38 \%$; $\mathrm{p}$ $<0.001)$. Glutamate did not induce a significant increase in LDH release, however, $100 \mu \mathrm{M}$ exposure resulted in a significant reduction in LDH release $(\mathrm{p}<0.0001)$ when compared to control cells. 

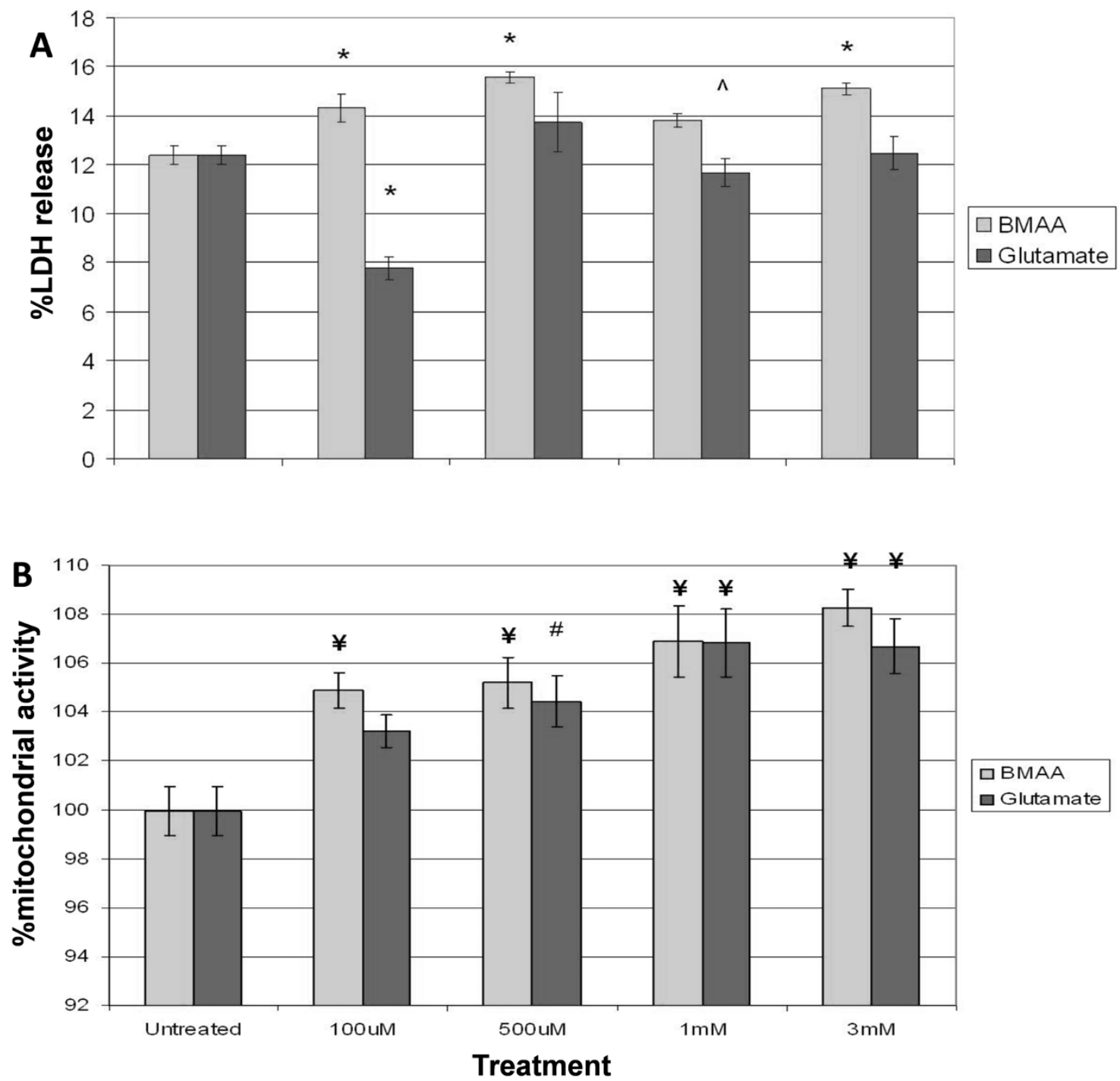

Figure $1 \mid$ LDH release and mitochondrial activity in OECs. (A) LDH release in OECs treated for $48 \mathrm{~h}$ with BMAA or glutamate. (B) Mitochondrial activity in OECs treated for $48 \mathrm{~h}$ with BMAA or glutamate. LDH and MTS assays were conducted simultaneously on cultures from a common plate. ${ }^{*} \mathrm{P}<0.01$ compared to control, ${ }^{*} \mathrm{P}<0.001$ compared to the control, ${ }^{\wedge} \mathrm{P}<0.05$ compared to the control. * $\mathrm{P}<0.02$ compared to control. Error bars represent SEM, $\mathrm{n}=5$.

Effect of BMAA on mitochondrial activity of OECs. BMAA and glutamate induced significant increases in mitochondrial activity at all concentrations studied. Similar increases of $6.89 \pm 1.48 \%(\mathrm{p}<$ $0.006)$ and $6.83 \pm 1.39 \%(\mathrm{p}<0.003)$ were observed for both BMAA and glutamate at $1 \mathrm{mM}$, respectively (Fig. 1B). The highest increase for BMAA was $8.28 \pm 0.76 \%(\mathrm{p}<0.002)$ at $3 \mathrm{mM}$.

BMAA associated changes to $\mathrm{Ca}^{2+}$ influx in OECs. A moderate, but significant $(\mathrm{p}<0.05)$, increase in $\mathrm{Ca}^{2+}$ influx was observed in OECs treated with $1 \mathrm{mM}$ BMAA and $\mathrm{HCO}_{3}{ }^{-}$. A greater influx was observed after treatment with $500 \mu \mathrm{M}$ and $1 \mathrm{mM}$ glutamate, both in the presence and absence of $\mathrm{HCO}_{3}{ }^{-}(\mathrm{p}<0.05)$ (Fig. 2).

BMAA associated generation of ROS. A significant increase ( $\mathrm{p}<$ $0.005)$ in the generation of ROS was observed in OECs treated with BMAA at $500 \mu \mathrm{M}(823 \pm 49 \%), 1 \mathrm{mM}(812 \pm 48 \%)$ and $3 \mathrm{mM}(756$ $\pm 20 \%)$ in the presence of $\mathrm{HCO}_{3}^{-}$(Fig. 3). Smaller, though significant $(\mathrm{p}<0.005)$, increases in ROS levels were observed in the absence of $\mathrm{HCO}_{3}{ }^{-}$in OECs treated with $1 \mathrm{mM}(283 \pm 10 \%)$

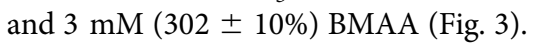

\section{Discussion}

In this study we conducted a series of assays to determine if the reported activities of BMAA on neurons also occur in glial cells. Toxicity of BMAA on glial cells would imply that it plays an important role in the onset of ALS, in particular, where glial cells are known to have a supportive role in the prevention of underlying neuronal damage and loss.

The 3-(4,5-dimethylthiazol-2-yl)-5-(3-carboxymethoxyphenyl)2-(4-sulfophenyl)-2H-tetrazolium (MTS) assay provides information pertaining to mitochondrial metabolic enzyme activities ${ }^{24}$. The MTS data obtained here indicated a significant increase in mitochondrial activity in glial cells treated with both BMAA and glutamate over a range of concentrations from $100 \mu \mathrm{M}$ to $3 \mathrm{mM}$ (Fig. 1B). Data for $\mathrm{LDH}$ release presented here indicated that BMAA can induce a significant increase in LDH release in OECs at $100 \mu \mathrm{M}$ (Fig 1A). These assays were conducted simultaneously using the same cultures, demonstrating that a reduction in the viability of OECs correlated directly with alterations in mitochondrial activity.

Calcium signalling is essential in regulating and maintaining neuronal function under physiological conditions. Disruption of $\mathrm{Ca}^{2+}$ homeostasis results in dysregulation of neurotransmitter release, 


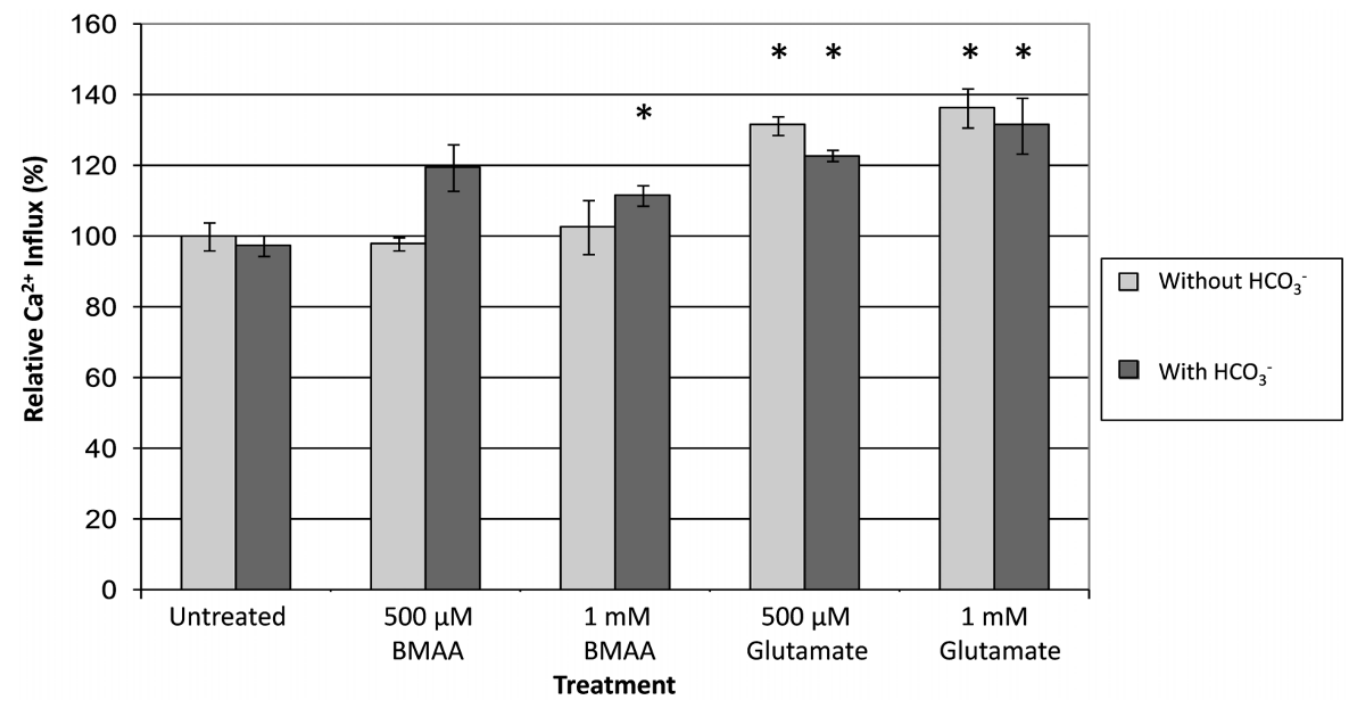

Figure $2 \mid \mathrm{Ca}^{2+}$ influx in OECs. Ca2 ${ }^{+}$influx of OECs treated with BMAA or glutamate. Fluorescence of fura-2-am was read (ex: $485 \mathrm{~nm}$, em: $520 \mathrm{~nm}$ ) immediately after addition of treatment conditions. ${ }^{*} \mathrm{P}<0.05$ compared to control. ${ }^{\wedge} \mathrm{P}<0.05$ compared to same treatment without $\mathrm{HCO}_{3}{ }^{-}$.

Error bars represent SEM, $\mathrm{n}=3$.

excitability, gene transcription, synaptic plasticity and cell survival ${ }^{25}$. Disruption of the intracellular $\mathrm{Ca}^{2+}$ ion concentration has been reported in rat and mouse neurons after exposure to BMAA at 1$5 \mathrm{mM}^{8,11}$. Our findings are in line with these reports on neuronal effects, with a significant increase in intracellular $\mathrm{Ca}^{2+}$ influx being observed in OECs at $1 \mathrm{mM}$ BMAA (Fig. 2). The observation that BMAA requires the presence of $\mathrm{HCO}_{3}{ }^{-}$in order to induce $\mathrm{Ca}^{2+}$ influx in OECs supports the proposal of Weiss and Choi that the glutamate homolog of BMAA, $\beta$-carbamate, represents the active form of $\mathrm{BMAA}^{26}$.

BMAA has also been shown to induce an increase in ROS generation in mouse neurons ${ }^{11,13,16}$. The present study demonstrated that exposure to BMAA at $500 \mu \mathrm{M}$ and above also increased ROS levels in glial cells, similar to the effect recently described in human neurons (Fig. 3) ${ }^{17}$. The increased generation of ROS in glial cells to around $800 \%$ is four-fold greater than any BMAA-induced increase previously reported ${ }^{13}$. The similarity between the observations of the effect of BMAA on OECs and our previous data using human neurons ${ }^{17}$ suggests that BMAA may also affect glial cells via a similar mechanism, notably excitotoxicity due to hyperactivation of EAA receptors.
The fact that BMAA also induced significant increases in ROS generation in the absence of $\mathrm{HCO}_{3}{ }^{-}(\sim 300 \%)$ suggested that it exerts an unknown mode of toxicity that does not utilize a glutamatergic pathway or EAA activation, but further adds to the oxidative stress load on neural tissues. Such significant increases in ROS generation are indicative of severely stressed mitochondria, which would lead to leakage of electrons from the respiratory chain into the cell ${ }^{27}$. The resulting free radicals, superoxide $\left(\mathrm{O}^{2-}\right)$ and hydrogen peroxide $\left(\mathrm{H}_{2} \mathrm{O}_{2}\right)$, would also likely undergo further reactions to produce more potent oxidizing agents capable of altering proteins and fatty acids, and damaging DNA and $\mathrm{RNA}^{27}$. In order to repair DNA damage the cells also require high levels of ATP, which in turn has a demand for efficiently functioning mitochondria ${ }^{27}$. Cells with mitochondrial dysfunction have been highlighted as being particularly vulnerable to oxidative stress ${ }^{25}$. In addition, deficient DNA repair systems have been linked to the development of ALS/PDC and $\mathrm{AD}^{28-30}$. The observed increase in mitochondrial activity in OECs may reflect the extra metabolic effort required by cells attempting to counter this incident damage they are incurring, as well as general dysfunction.

The non-cell autonomous death hypothesis proposes that the death of neuronal cells occurs indirectly as a consequence of

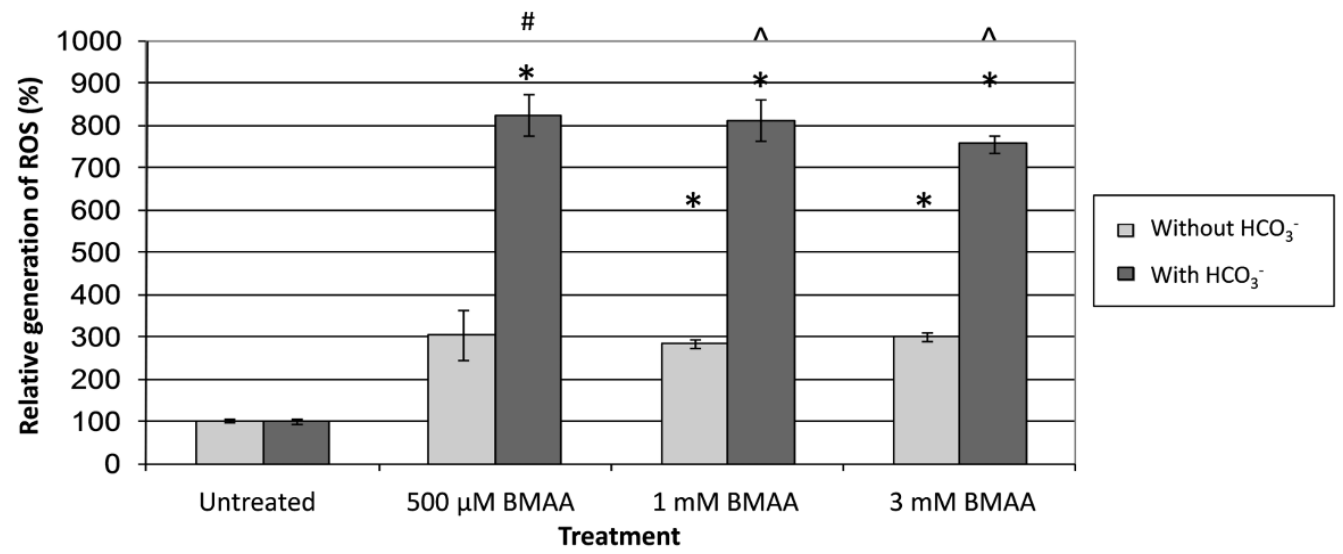

Figure 3 Generation of ROS in OECs. Generation of ROS in OECs treated with BMAA, with and without $\mathrm{HCO}_{3}{ }^{-}$. Fluorescence of DCFDA was read (ex: $485 \mathrm{~nm}$, em: $535 \mathrm{~nm}$ ) at 0 (background) and 60 min after addition of treatments. ${ }^{*} \mathrm{P}<0.005$ compared to the untreated control. ${ }^{*} \mathrm{P}<0.003$ compared to same sample without $\mathrm{HCO}_{3}{ }^{-} .{ }^{\wedge} \mathrm{P}<0.001$ compared to same sample without $\mathrm{HCO}_{3}{ }^{-}$. Error bars represent $\mathrm{SEM}, \mathrm{n}=3$. 
deficiencies in their supporting cells and neurotrophic factors ${ }^{23}$. If glial cells or these factors are inhibited or damaged, the neuronal cells that they support will also be compromised. This hypothesis is supported by the improved survival of diseased animals after transplantation with neural nurse cells or stem cells, including the use of OECs ${ }^{31-33}$. Therefore, any alteration to these neuronal support cells could be a major contributor to the progression of neural degeneration $^{23,34}$.

Since neurons perform a highly specialised function and are limited in many metabolic pathways, most of their basic requirements are provided by the surrounding glial cells. Dysfunctional glial cells would therefore increase the vulnerability of neurons to excitotoxic stress agents, such as BMAA, thereby contributing to the overall effect of exposure to the agent ${ }^{23}$. An increase in the oxidative stress load in neurons leads to increases in damage to cellular proteins, lipids and cellular biochemistry ${ }^{34}$. Physiologically glial cells should provide support and protection for neurons, however, ROS generated by glial cells has been shown to induce neuronal damage in $v i v o^{35}$. In the present study, we observed a substantial increase in the generation of ROS in OECs $(>800 \%)$ compared to the control cells. When exposed to BMAA, primary neurons would therefore be under injurious and sustained oxidative attack from these surrounding cells that would otherwise protect them from such insults. This single observation strongly supports the non-cell autonomous death mechanism of ALS progression ${ }^{23,34}$.

While we have shown that there are statistically significant effects of BMAA on OECs, those effects are not as large as those observed in a recent report where similar assays were conducted on primary neurons ${ }^{17}$. The peak LDH release in OECs (Fig. 1A) displayed an approximate $30 \%$ increase, whereas in primary neurons it was more than $400 \%$ higher than the control ${ }^{17}$. In addition, the observed increase in $\mathrm{Ca}^{2+}$ influx was greater in primary neurons than in OECs. This indicated that primary neurons are generally more sensitive and vulnerable to damage from direct exposure to BMAA compared to their protective glial cells.

These observations direct us to an interesting hypothesis that may be explained by the disease with which BMAA has been associated. ALS is generally a late onset disease with people only presenting symptoms in their middle age ${ }^{23}$ despite likely being exposed to its causative agent(s) for the majority of their lives. Data presented in previous studies has shown that neurons are quite sensitive and easily damaged following direct exposure to BMAA. As glial cells surround the neurons in vivo, they may be capable of effectively shielding neurons from BMAA exposure, as long as they maintain relatively normal function. The assays conducted in this study were performed over $48 \mathrm{~h}$, and we have described the significant changes this exposure induced. In the case of environmental exposure to agents, such as BMAA, the exposure periods are almost certain to be much longer than $48 \mathrm{~h}$, particularly if the bioaccumulation hypothesis of BMAA is accurate $^{36}$. It is highly likely that longer exposure periods, even at lower doses, could lead to greater damage occurring to glial cells, culminating in apoptotic cell death. This may correlate with the point of onset of disease symptoms and diagnosis. The failure and death of glial cells not only deprives sensitive neurons of the support they require to efficiently function, but also leaves them vulnerable to direct insult, which they have been demonstrated to be particularly sensitive to. This may explain the relatively short time period between diagnosis/disease onset and death observed in sufferers. If this hypothesis is correct, attention should be focused on identifying the complete pathway of BMAA toxicity, primarily the etiology of early glial cell damage. This could also provide earlier detection of the disease state, and potentially identify key treatment targets, enabling a better chance of reducing neurodegeneration attributable to BMAA or similar environmental exposures.

In this study, we have assessed the cytotoxicity of BMAA on primary cultures of rat OECs. We have demonstrated that these cells are significantly compromised after treatment with BMAA. The data suggest that BMAA can act on OECs by at least two different mechanisms, those being direct excitotoxicity as well as disturbance of mitochondrial activity. These results also represent the first evidence for the potential role of BMAA in gliotoxicity, aligning it with the third proposed mechanism of ALS progression, that being noncell autonomous death. These findings therefore provide further evidence indicating that BMAA has the potential to play a major role in neurodegenerative conditions globally due to its reported ubiquitous environmental exposure.

\section{Methods}

Animal ethics approval. Five week-old Wistar rats were anaesthetized with sodium pentobarbital (100 $\mathrm{mg} \mathrm{kg}^{-1}$ i.p.), sacrificed by decapitation and the heads bisected sagittally. All animal experiments were approved by the Animal Care and Ethics Committee at the University of New South Wales (06/53A).

Isolation and culture of olfactory ensheathing cells (OECs). The isolation method used was previously described by Marçal et al. ${ }^{37}$. Briefly, cells were surgically removed from the rats before being placed into $75 \mathrm{~cm}^{2}$ culture flasks containing $15 \mathrm{ml} \mathrm{OEC}$ expansion media containing Dulbecco's modified eagle media (DMEM) (Cambrex) supplemented with $50 \mathrm{ng} / \mathrm{mL}$ Neurotrophin-3 (Sigma-Aldrich) ${ }^{38}$. Following isolation the OECs were maintained in DMEM media (containing $44 \mathrm{mM}$ $\mathrm{HCO}_{3}{ }^{-}$) supplemented with $10 \%$ FBS (Gibco) in $75 \mathrm{~cm}^{2}$ culture flasks. All OEC assays were conducted in this medium unless otherwise stated. For all assays, cells were seeded into 96-well plates at 4000 cells/well. Cells were incubated overnight following plate seeding before assays were commenced. All cell culture supplements were supplied by Invitrogen unless otherwise stated. All cells were incubated at $37^{\circ} \mathrm{C}$ with $5 \% \mathrm{CO}_{2}$

3-(4,5-dimethylthiazol-2-yl)-5-(3-carboxymethoxyphenyl)-2-(4-sulfophenyl)2H-tetrazolium (MTS) assay for mitochondrial activity. MTS and LDH assays were conducted simultaneously in DMEM supplemented with 5\% heat inactivated FBS (Gibco). Cells were exposed to treatment conditions for $48 \mathrm{~h}$ prior to the MTS assay being conducted. MTS reagent (Promega) was added to each well and incubated for $4 \mathrm{~h}$ before the absorbance was read at $490 \mathrm{~nm}$ and $690 \mathrm{~nm}$ (VersaMax, Molecular Devices). The $690 \mathrm{~nm}$ readings were subtracted from the $490 \mathrm{~nm}$ readings as background. The data is presented as a \% metabolism compared to an untreated sample that was considered to be $100 \%$ (normal) metabolic activity.

Lactate dehydrogenase (LDH) release. The release of $\mathrm{LDH}$ into the culture media correlates with the amount of cell death and membrane damage in the treated population, providing an accurate measure of cellular toxicity. Cells were exposed to treatment conditions for $48 \mathrm{~h}$ prior to the $\mathrm{LDH}$ release assay being conducted. Briefly the media in each well was mixed thoroughly and $50 \mu \mathrm{L}$ was transferred to a 96-well plate. LDH activity (indicating relative release amounts) was measured in each well as per the manufacturers protocol (Sigma). The plate was incubated for $90 \mathrm{~min}$ before the absorbance was read at $490 \mathrm{~nm}$ and $690 \mathrm{~nm}$ (VersaMax, Molecular Devices). $690 \mathrm{~nm}$ readings were subtracted from $490 \mathrm{~nm}$ readings as background. The data is normalised against a lysed healthy cell sample that was considered to be $100 \%$ release.

$\mathrm{Ca}^{2+}$ influx assay. Intracellular $\mathrm{Ca}^{2+}$ influx was measured in OECs as previously described $^{39}$. Briefly, cells were incubated concomitantly with $3.5 \mu \mathrm{g} / \mathrm{ml}$ Fura-2-AM (Molecular Probes) prepared in Hanks balanced salt solution (HBSS) (Gibco) supplemented with $50 \mathrm{mM}$ glycine (Sigma) at $37^{\circ} \mathrm{C}$ for $1 \mathrm{~h}$. Treatment chemicals were diluted in HBSS. Fluorescence was read with an excitation wavelength of $485 \mathrm{~nm}$ and an emission wavelength of $535 \mathrm{~nm}$. The data is presented as a $\%$ of $\mathrm{Ca}^{2+}$ influx relative to an untreated sample where $100 \%$ is considered to be normal influx.

\section{$2^{\prime}, 7^{\prime}$-Dichlorofluorescin diacetate (DCFDA) assay for production of reactive} oxygen species. Cells were incubated in $10 \mu \mathrm{M}$ DCFDA (Sigma) in PBS at $37^{\circ} \mathrm{C}$ for $30 \mathrm{~min}$. Treatments were added in PBS. After addition of treatments, fluorescence was measured at $0 \mathrm{~min}$ and $60 \mathrm{~min}$ with an excitation wavelength of $485 \mathrm{~nm}$ and an emission wavelength of $535 \mathrm{~nm}$. The initial zero point readings were subtracted from the 60 min readings as the assay background. The data is presented as a \% of an untreated sample that was deemed to be $100 \%$ (normal ROS generation level).

Treatment compounds. BMAA, glutamate and sodium bicarbonate were supplied by Sigma. All chemicals used to challenge the OECs were dissolved in filtered milliQ water.

Data analysis. Results obtained in this study are presented as the means \pm the standard error of measurement (SEM). LDH and MTS assays were performed in quintuplicate. $\mathrm{Ca}^{2+}$ influx and DCFDA assays were conducted in triplicate. Replicates were assays performed in different culture vessels. One-way analysis of variance (ANOVA) and post hoc Tukey's multiple comparison tests were used to determine the statistical significance between treatment groups. 
1. Kurland, L. T. \& Mulder, D. W. Epidemiologic investigations of amyotrophic lateral sclerosis. I. Preliminary report on geographic distribution and special reference to the Mariana Islands, including clinical and pathologic observations. Neurology 4, 438-448 (1954).

2. Arnold, A., Edgren, D. C. \& Palladino, V. S. Amyotrophic lateral sclerosis; fifty cases observed on Guam. The Journal of Nervous and Mental Disease 117, 135-139 (1953).

3. Kurland, L. T. \& Mulder, D. W. Epidemiologic investigations of amyotrophic lateral sclerosis. I. Preliminary report on geographic distribution, with special reference to the Mariana Islands, including clinical and pathologic observations. Neurology 4, 355-378 (1954).

4. Murch, S. J., Cox, P. A., Banack, S. A., Steele, J. C. \& Sacks, O. W. Occurrence of $\beta$-methylamino-l-alanine (BMAA) in ALS/PDC patients from Guam. Acta Neurologica Scandinavica 110, 267-269 (2004).

5. Pablo, J. et al. Cyanobacterial neurotoxin BMAA in ALS and Alzheimer's disease. Acta Neurologica Scandinavica 120, 216-225 (2009).

6. Murch, S. J., Cox, P. A. \& Banack, S. A. A mechanism for slow release of biomagnified cyanobacterial neurotoxins and neurodegenerative disease in Guam. Proceedings of the National Academy of Sciences of the United States of America 101, 12228-12231 (2004).

7. Chiu, A. S., Gehringer, M. M., Welch, J. H. \& Neilan, B. A. Does alpha-aminobeta-methylaminopropionic acid (BMAA) play a role in neurodegeneration? International journal of environmental research and public health 8, 3728-3746 (2011).

8. Brownson, D. M., Mabry, T. J. \& Leslie, S. W. The cycad neurotoxic amino acid, B-N-methylamino--alanine (BMAA), elevates intracellular calcium levels in dissociated rat brain cells. Journal of Ethnopharmacology 82, 159-167 (2002).

9. Choi, D. W. Glutamate neurotoxicity and diseases of the nervous system. Neuron 1, 623-634 (1988)

10. Meldrum, B. \& Garthwaite, J. Excitatory amino acid neurotoxicity and neurodegenerative disease. Trends in Pharmacological Sciences 11, 379-387 (1990)

11. Rao, S. D., Banack, S. A., Cox, P. A. \& Weiss, J. H. BMAA selectively injures motor neurons via AMPA/kainate receptor activation. Experimental Neurology 201, 244-252 (2006).

12. Richter, K. E. \& Mena, E. E. L-beta-methylaminoalanine inhibits [3H]glutamate binding in the presence of bicarbonate ions. Brain Research 492, 385-388 (1989).

13. Lobner, D., Piana, P. M. T., Salous, A. K. \& Peoples, R. W. [beta]-N-methylaminol-alanine enhances neurotoxicity through multiple mechanisms. Neurobiology of Disease 25, 360-366 (2007)

14. Nedeljkov, V., Lopicic, S., Pavlovic, D. \& Cemerikic, D. Electrophysiological Effect of $\beta$-N-Methylamino-L-Alanine on Retzius Nerve Cells of the Leech Haemopis sanguisuga. Annals of the New York Academy of Sciences 1048, 349-351 (2005).

15. Copani, A. et al. Interaction between beta-N-methylamino-L-alanine and excitatory amino acid receptors in brain slices and neuronal cultures. Brain Research 558, 79-86 (1991).

16. Liu, X., Rush, T., Zapata, J. \& Lobner, D. [beta]-N-methylamino-l-alanine induces oxidative stress and glutamate release through action on system $\mathrm{Xc}^{-}$. Experimental Neurology 217, 429-433 (2009).

17. Chiu, A. S. et al. Excitotoxic potential of the cyanotoxin $\beta$-methyl-amino- ${ }^{-}$ alanine (BMAA) in primary human neurons. Toxicon 60, 1159-1165 (2012)

18. Doucette, J. R. The glial cells in the nerve fiber layer of the rat olfactory bulb. The Anatomical Record 210, 385-391 (1984).

19. Murrell, W. et al. Neurogenesis in adult human. Neuroreport 7, 1189-1194 (1996).

20. Mackay-Sim, A. Olfactory ensheathing cells and spinal cord repair. The Keio Journal of Medicine 54, 8-14 (2005).

21. Viktorov, I. V., Savchenko, E. A., Ukhova, O. V., Alekseyeva, N. Y. \& Chekhonin, V.P. Multipotent stem and progenitor cells of the olfactory epithelium. Bulletin of Experimental Biology and Medicine 142, 495-502 (2006).

22. Gallo, V. \& Ghiani, C. A. Glutamate receptors in glia: new cells, new inputs and new functions. Trends in Pharmacological Sciences 21, 252-258 (2000).

23. Boillee, S., Vande Velde, C. \& Cleveland, D. W. ALS: A Disease of Motor Neurons and Their Nonneuronal Neighbors. Neuron 52, 39-59 (2006).

24. Cory, A. H., Owen, T. C., Barltrop, J. A. \& Cory, J. G. Use of an aqueous soluble tetrazolium/formazan assay for cell growth assays in culture. Cancer Communications 3, 207-212 (1991).
25. Wang, X. \& Michaelis, E. K. Selective neuronal vulnerability to oxidative stress in the brain. Frontiers in Aging Neuroscience 2, 12 (2010).

26. Weiss, J. H. \& Choi, D. W. Beta-N-methylamino-L-alanine neurotoxicity: requirement for bicarbonate as a cofactor. Science 241, 973-975 (1988).

27. Stadtman, E. Protein oxidation and aging. Science 257, 1220-1224 (1992).

28. Robbins, J. H. et al. Parkinson's disease and Alzheimer's disease: hypersensitivity to X rays in cultured cell lines. Journal of Neurology, Neurosurgery \& Psychiatry 48, 916-923 (1985)

29. Mazzarello, P., Poloni, M., Spadari, S. \& Focher, F. DNA repair mechanisms in neurological diseases: facts and hypotheses. Journal of the Neurological Sciences 112, 4-14 (1992).

30. Lovell, M. A., Xie, C. \& Markesbery, W. R. Decreased base excision repair and increased helicase activity in Alzheimer's disease brain. Brain Research $\mathbf{8 5 5}$ 116-123 (2000)

31. Cozzolino, M., Ferri, A. \& Teresa Carri, M. Amyotrophic Lateral Sclerosis: From Current Developments in the Laboratory to Clinical Implications. Antioxidants \& Redox Signaling 10, 405-444 (2008).

32. Corti, S. et al. Neural stem cells LewisX + CXCR4+ modify disease progression in an amyotrophic lateral sclerosis model. Brain 130, 1289-1305 (2007).

33. Garbuzova-Davis, S. et al. Intravenous administration of human umbilical cord blood cells in a mouse model of amyotrophic lateral sclerosis: distribution, migration, and differentiation. Journal of Hematotherapy and Stem Cell Research 12, 255-270 (2003)

34. Shaw, P. J. Molecular and cellular pathways of neurodegeneration in motor neurone disease. Journal of Neurology, Neurosurgery \& Psychiatry 76, 1046-1057 (2005).

35. Kabashi, E., Valdmanis, P. N., Dion, P. \& Rouleau, G. A. Oxidized/misfolded superoxide dismutase-1: the cause of all amyotrophic lateral sclerosis? Annals of Neurology 62, 553-559 (2007).

36. Cox, P. A. \& Sacks, O. W. Cycad neurotoxins, consumption of flying foxes, and ALS-PDC disease in Guam. Neurology 58, 956-959 (2002).

37. Marçal, H. et al. Expression proteomics of olfactory ensheathing cells. Journal of Chemical Technology and Biotechnology 83, 473-481 (2008)

38. Bianco, J. I., Perry, C., Harkin, D. G., Mackay-Sim, A. \& Féron, F. Neurotrophin 3 promotes purification and proliferation of olfactory ensheathing cells from human nose. Glia 45, 111-123 (2004).

39. Braidy, N., Grant, R., Adams, S. \& Guillemin, G. J. Neuroprotective effects of naturally occurring polyphenols on quinolinic acid-induced excitotoxicity in human neurons. FEBS Journal 277, 368-382 (2010)

\section{Acknowledgements}

This work was funded by the Australian Research Council, the University of New South Wales and the Association pour la Recherche sur la Sclérose Amyotrophique Latérale. BAN and GJG are fellows of the Australian Research Council. NB is a fellow of the Alzheimer's Australia Viertel Foundation.

\section{Author contributions}

A.S.C. performed the experiments, analysed the data, wrote the manuscript and prepared the figures. N.B. assisted with the statistical analysis. All authors assisted with experimental design and reviewed the manuscript.

\section{Additional information}

Competing financial interests: The authors declare no competing financial interests.

License: This work is licensed under a Creative Commons

Attribution-NonCommercial-NoDerivs 3.0 Unported License. To view a copy of this license, visit http://creativecommons.org/licenses/by-nc-nd/3.0/

How to cite this article: Chiu, A.S. et al. Gliotoxicity of the cyanotoxin,

$\beta$-methyl-amino- ${ }^{-}$-alanine (BMAA). Sci. Rep. 3, 1482; DOI:10.1038/srep01482 (2013). 